Article

\title{
Tricycloalternarene Analogs from a Symbiotic Fungus Aspergillus sp. D and Their Antimicrobial and Cytotoxic Effects
}

\author{
Huawei Zhang ${ }^{1}{ }^{(D)}$, Ziping Zhao ${ }^{1}$, Jianwei Chen ${ }^{1}$, Xuelian Bai ${ }^{2}$ and Hong Wang ${ }^{1, *}$ \\ 1 School of Pharmaceutical Sciences, Zhejiang University of Technology, Hangzhou 310014, China; \\ hwzhang@zjut.edu.cn (H.Z.); marinedrugs2017@163.com (Z.Z.); cjw983617@zjut.edu.cn (J.C.) \\ 2 College of Life and Environmental Sciences, Hangzhou Normal University, Hangzhou 310038, China; \\ baix12012@163.com \\ * Correspondence: hongw@zjut.edu.cn; Tel.: +86-571-8832-0622
}

Received: 19 March 2018; Accepted: 5 April 2018; Published: 9 April 2018

\begin{abstract}
Bioassay-guided fractionation of the crude extract of fermentation broth of one symbiotic strain Aspergillus sp. D from the coastal plant Edgeworthia chrysantha Lindl. led to isolation of one new meroterpenoid, tricycloalternarene $14 \mathrm{~b}(\mathbf{1})$, together with four known analogs (2-5), tricycloalternarenes $2 b(2), 3 a(3), 3 b$ (4), and ACTG-toxin F (5). Their chemical structures were unambiguously established on the basis of NMR, mass spectrometry, and optical rotation data analysis, as well as by comparison with literature data. Biological assays indicated that compound 2 exhibited potent in vitro cytotoxicity against human lung adenocarcinoma A549 cell line with an $\mathrm{IC}_{50}$ value of $2.91 \mu \mathrm{M}$, and compound $\mathbf{5}$ had a moderate inhibitory effect on Candida albicans, with an MIC value of $15.63 \mu \mathrm{M}$. The results indicated that this symbiotic strain $\mathrm{D}$ is an important producer of tricycloalternarene derivatives, with potential therapeutic application in treatment of cancer and pathogen infection.
\end{abstract}

Keywords: tricycloalternarene; meroterpenoid; Aspergillus sp.; Edgeworthia chrysantha Lindl.; symbiotic microbe; coastal plant

\section{Introduction}

The fungi of the Aspergillus genus are well known to be a rich source of secondary metabolites with a broad spectrum of biological activities. The Aspergillus Secondary Metabolites Database (A2MDB) had documented 807 unique non-redundant natural products derived from 675 Aspergillus species by 2017 [1]. A growing amount of evidence also indicates that symbiotic Aspergillus strains are an important contributor of bioactive natural products. By 2014, up to 162 new bioactive chemicals had been characterized from 11 Aspergilli spp. as endophytic microbes [2]. Tricycloalternarenes (TCAs) represent a group of fungal-derived meroterpenoids, and are produced by several genera, including Aspergillus [3], Alternaria [4-6], Guignardia [7], Ulocladium [8], etc. Structurally, TCAs are closely related to ACTG-toxins. The differences mainly occur in the isoprenoid side chain and the substitution pattern of the C-ring of TCAs. These metabolites are of intense interest to natural drug chemists due to their remarkable antimicrobial and cytotoxic effects.

In our ongoing chemical investigation of symbiotic Aspergillus strains for discovery of new bioactive natural products, one new meroterpenoid, named TCA $14 \mathrm{~b}(\mathbf{1})$, along with four derivatives, TCAs 2b (2), 3a (3), 3b (4), and ACTG-toxin F (5), was isolated from Aspergillus sp. D associated with the coastal plant Edgeworthia chrysantha Lindl (Figure 1). Details on the isolation and structural elucidation of these compounds are reported in this paper, as well as the results of cytotoxic and antimicrobial assays. 


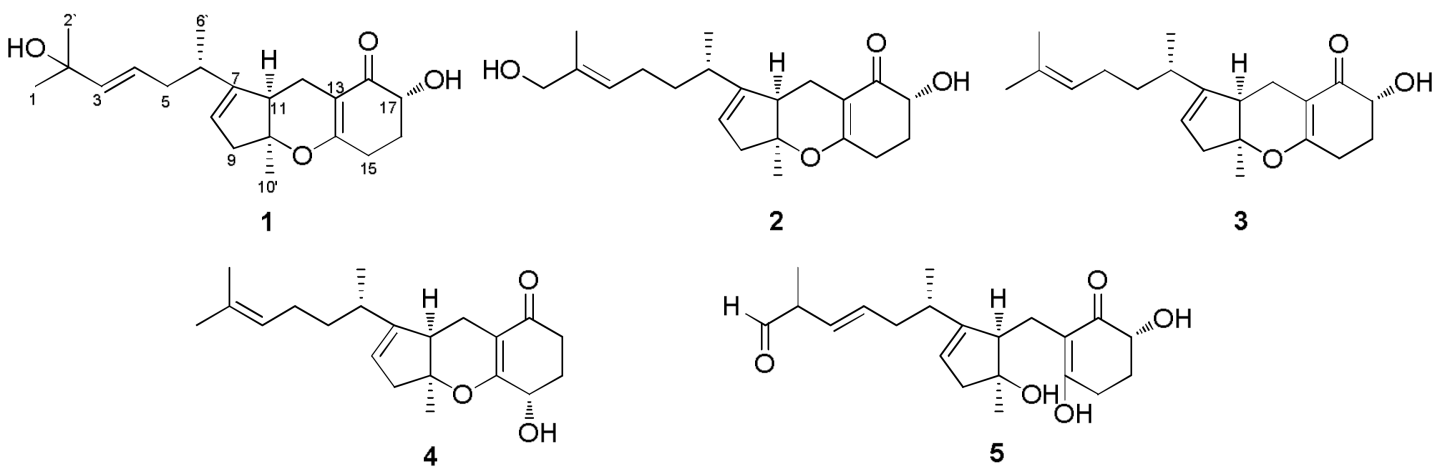

Figure 1. Chemical structures of compounds 1-5.

\section{Results and Discussion}

Bioassay-guided fractionation of the EtOAc crude extract of fermentation broth of the strain D led to isolation of five compounds (1-5) using the semi-preparative and analytical HPLC approach. The chemical structures of compounds 2-5 were assigned as TCAs $2 b(2), 3 a(3), 3 b$ (4) and ACTG-toxin F (5) based on spectroscopic comparisons with literature data [9-13]. A structure argument for the new compound $\mathbf{1}$ is described below.

Compound 1 was obtained as yellowish amorphous powder. Its positive HR-ESI-MS at $m / z$ $369.2039[\mathrm{M}+\mathrm{Na}]^{+}$indicated a molecular formula of $\mathrm{C}_{21} \mathrm{H}_{30} \mathrm{O}_{4}$ with 7 degrees of unsaturation (calcd. for $\mathrm{C}_{21} \mathrm{H}_{30} \mathrm{O}_{4} \mathrm{Na}$ 369.2036), which is isomeric to TCA $2 \mathrm{~b}$ (2). The ${ }^{1} \mathrm{H}-\mathrm{NMR}$ spectrum of 1 showed a good agreement with that of compound 2 (Supplementary Material). In order to facilitate structure elucidation, the ${ }^{1} \mathrm{H}$ and ${ }^{13} \mathrm{C}-\mathrm{NMR}$ data for $\mathbf{1}$ and $\mathbf{2}$ are listed in Table 1. Careful inspection of proton NMR, HSQC and COSY spectra suggested that compound 1 has a [5,6,6] heterocyclic moiety and one 2-methyl-heptenic group at C-7. In contrast to 2 , however, compound 1 possesses one more olefinic proton $\left(\delta_{\mathrm{H}} 5.50\right)$ and one more methyl $\left(\delta_{\mathrm{H}}\right.$ 1.29). It was deduced that the double bond between C-2 and C-3 in 2 was transferred to the position of C-3 and C-4 in 1, while the hydroxyl group at C-1 in 2 was moved to C-2 in 1. This assumption was certified by the observed variation of their ${ }^{13} \mathrm{C}-\mathrm{NMR}$ data, in which the chemical shift values of C-1 (68.7), C-2 (135.2) and C-4 (24.9) in 2 were changed to 29.8, 70.7, 125.2, respectively, in 1 (Table 1). The planar structure of 1 was further verified by its key ${ }^{1} \mathrm{H}-{ }^{1} \mathrm{H}$ COSY and HMBC correlations from $\mathrm{H}-3$ to C-2, C-2' and C-5, and from H-4 to C-2, C-3 and C-5 (Figure 2).

Table 1. The ${ }^{1} \mathrm{H}-\mathrm{NMR}(500 \mathrm{MHz})$ and ${ }^{13} \mathrm{C}-\mathrm{NMR}(500 \mathrm{MHz})$ data of compound $\mathbf{1}$ (in $\left.\mathrm{CDCl}_{3}\right)$.

\begin{tabular}{|c|c|c|c|c|}
\hline \multirow{2}{*}{ Position } & \multicolumn{2}{|c|}{1} & \multicolumn{2}{|c|}{2} \\
\hline & $\delta_{\mathrm{H}}(J$ in $\mathrm{Hz})$ & $\delta_{C}$ & $\delta_{\mathrm{H}}(J$ in $\mathrm{Hz})$ & $\delta_{C}$ \\
\hline 1 & $1.29(3 \mathrm{H}, \mathrm{s})$ & 29.8 & $3.95(2 \mathrm{H}, \mathrm{s})$ & 68.7 \\
\hline 2 & & 70.7 & & 135.2 \\
\hline $2^{\prime}$ & $1.29(3 \mathrm{H}, \mathrm{s})$ & 29.8 & $1.62(3 \mathrm{H}, \mathrm{s})$ & 23.2 \\
\hline 3 & $5.59(\mathrm{H}, \mathrm{d}, 15.6)$ & 139.6 & $5.25(\mathrm{H}, \mathrm{t}, 7.6)$ & 125.4 \\
\hline 4 & $5.50(\mathrm{H}, \mathrm{m})$ & 125.2 & $2.01(2 \mathrm{H}, \mathrm{m})$ & 24.9 \\
\hline 5 & $\begin{array}{l}1.97(\mathrm{H}, \mathrm{m}) \\
2.23(\mathrm{H}, \mathrm{m})\end{array}$ & 27.8 & $1.50(2 \mathrm{H}, \mathrm{m})$ & 34.6 \\
\hline 6 & $2.08(\mathrm{H}, \mathrm{m})$ & 32.8 & $1.90(\mathrm{H}, \mathrm{m})$ & 31.1 \\
\hline $6^{\prime}$ & $0.96,(3 \mathrm{H}, \mathrm{d}, 6.9)$ & 19.4 & $0.96(3 \mathrm{H}, \mathrm{d}, 6.9)$ & 13.7 \\
\hline 7 & & 149.7 & & 150.0 \\
\hline 8 & $5.33(\mathrm{H}, \mathrm{s})$ & 120.4 & $5.34(\mathrm{H}, \mathrm{s})$ & 119.9 \\
\hline 9 & $\begin{array}{l}2.43(\mathrm{H}, \mathrm{m}) \\
2.60(\mathrm{H}, \mathrm{m})\end{array}$ & 44.9 & $\begin{array}{l}2.36(\mathrm{H}, \mathrm{m}) \\
2.60(\mathrm{H}, \mathrm{m})\end{array}$ & 45.1 \\
\hline 10 & & 88.3 & & 88.8 \\
\hline $10^{\prime}$ & $1.43(3 \mathrm{H}, \mathrm{s})$ & 23.4 & $1.45(3 \mathrm{H}, \mathrm{s})$ & 20.2 \\
\hline 11 & $2.75(\mathrm{H}, \mathrm{m})$ & 46.3 & $2.77(\mathrm{H}, \mathrm{m})$ & 46.5 \\
\hline
\end{tabular}


Table 1. Cont

\begin{tabular}{ccccc}
\hline \multirow{2}{*}{ Position } & \multicolumn{2}{c}{$\mathbf{c} 2$} \\
\cline { 2 - 5 } & $\delta_{\mathbf{H}}(\boldsymbol{J}$ in Hz) & $\delta_{\mathbf{C}}$ & $\delta_{\mathbf{H}}(\boldsymbol{J}$ in Hz) & $\delta_{\mathbf{C}}$ \\
\hline \multirow{2}{*}{12} & $2.49(\mathrm{H}, \mathrm{m})$ & 15.4 & $2.17(\mathrm{H}, \mathrm{m})$ & 14.9 \\
13 & $2.73(\mathrm{H}, \mathrm{m})$ & 105.2 & & 105.1 \\
14 & & 171.8 & $2.73(\mathrm{H}, \mathrm{m})$ & 172.9 \\
15 & $2.34(\mathrm{H}, \mathrm{m})$ & 29.3 & $2.53(\mathrm{~m})$ & 27.8 \\
& $2.49(\mathrm{H}, \mathrm{m})$ & & $1.73(\mathrm{H}, \mathrm{m})$ & 29.4 \\
16 & $1.77(\mathrm{H}, \mathrm{m})$ & $2.32(\mathrm{H}, \mathrm{m})$ & 71.0 \\
18 & $2.08(\mathrm{H}, \mathrm{m})$ & 71.6 & $4.02(\mathrm{H}, \mathrm{dd}, 12.9,5.4)$ & 197.8 \\
\hline
\end{tabular}

The configuration of the double bond between C-3 and C-4 in compound $\mathbf{1}$ was determined as $E$ based on its ${ }^{3} J_{3-4}$ value of $15.6 \mathrm{~Hz}$. Its relative configuration was established on the basis of the important NOESY correlations of $\mathrm{H}-11$ to $\mathrm{H}_{3}-6^{\prime}$ and $\mathrm{H}_{3}-10^{\prime}$ (Figure 3) and the optical rotation $\left([\alpha]_{D}^{25}=+78^{\circ}\right)$, which was similar to that of compound 2 . Hence, $\mathbf{1}$ was identified as a new natural product and named as TCA $14 \mathrm{~b}$.

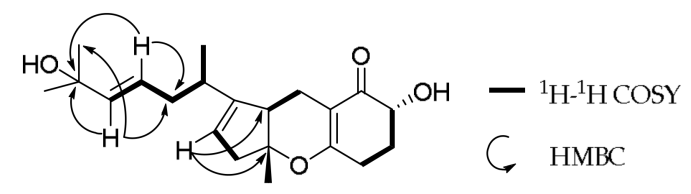

Figure 2. Key ${ }^{1} \mathrm{H}-{ }^{1} \mathrm{H}$ COSY and HMBC correlations of $\mathbf{1}$.

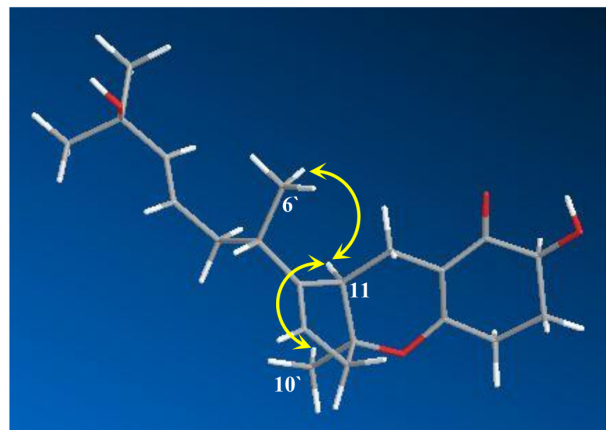

Figure 3. Strong NOESY correlations observed in $\mathbf{1 .}$

All isolated metabolites (1-5) were subjected to antimicrobial evaluation on three human pathogenic strains (Escherichia coli, Staphyloccocus aureus and Candida albicans) and preliminary cytotoxicity screening in vitro using CCK-8 assay against human lung carcinoma A-549 cell. Bioassay results showed that compounds 1-5 exhibited selective inhibitory effects on E. coli, S. aureus, C. albicans and A-549. Only ACTG-toxin F (5) clearly inhibited the growth of C. albicans, with an MIC value of $15.63 \mu \mathrm{M}$, whereas weak inhibition was observed for other compounds (MIC $\geq 31.25 \mu \mathrm{M}$ ). Compounds 1-5 possessed a moderate cytotoxic effect against human lung carcinoma A-549, with $\mathrm{IC}_{50}$ values of $8.89,1.43,10.35,2.90$, and $15.77 \mu \mathrm{M}$, respectively. 


\section{Experimental Section}

\subsection{General Experimental Procedures}

NMR spectra were recorded on a $500 \mathrm{MHz}$ Bruker Avance DRX500 spectrometer (Bruker, Fällande, Switzerland) equipped with a $5 \mathrm{~mm}$ triple resonance (HCN) cold probe, using TMS as an internal standard. Melting points were measured on a XRC-1 apparatus (Sichuang University Science and Education Instrument Factory, Chengdu, China) and were uncorrected. Optical rotations were obtained on a JASCO P-2000 polarimeter (JASCO, Fukuoka, Japan). Ultraviolet (UV) spectra were recorded on Hitachi-UV-3000 spectrometer (Hitachi, Tokyo, Japan), and FT-IR spectra were determined on Nexus 870 spectrometer (Thermo Nicolet, Madison, WI, USA). ESI-MS and HR-ESI-MS data were taken on an Agilent 6210 LC/TOF-MS spectrometer (Agilent Technologies, Santa Clara, CA, USA). Purification of all compounds was performed on Waters D600 apparatus (Waters, San Diego, CA, USA) equipped with a semi-preparative column (YMC-PACK-ODS-A, $250 \times 10 \mathrm{~mm}, 5 \mu \mathrm{m}, \mathrm{YMC}$, Kyoto, Japan) and an analytical column (Synergi Hydro-RP, $250 \mathrm{~mm} \times 4.6 \mathrm{~mm}, 4 \mu \mathrm{m}$, Phenomenex, Torrance, CA, USA). Acetonitrile (Merck, Darmstadt, Germany) and $\mathrm{H}_{2} \mathrm{O}$ used in HPLC system were of chromatographic grade, and all other chemicals were analytical.

\subsection{Fungal Materials}

Fungal strain D was isolated from the healthy leaves of the coastal plant Edgeworthia chrysantha Lindl., collected from Hangzhou Bay, China. The culture was grown on potato dextrose agar (PDA) and identified as Aspergillus sp. on the basis of its morphological characteristics and analysis of $18 \mathrm{~S}$ rDNA gene sequence (GenBank accession No. KR019681). This fungus is maintained as a cryopreserved glycerol stock at School of Pharmaceutical Sciences, Zhejiang University of Technology, China.

\subsection{Fermentation, Extraction, and Isolation}

Strain D was cultured on PDA at $28{ }^{\circ} \mathrm{C}$ for 7 days. A balanced amount of fungal colony was transferred to culture broth in 500-mL Erlenmeyer flask, which contained $250 \mathrm{~mL}$ salted Czapek's medium consisting of sucrose $30 \mathrm{~g} / \mathrm{L}, \mathrm{NaCl} 30 \mathrm{~g} / \mathrm{L}, \mathrm{NaNO}_{3} 3 \mathrm{~g} / \mathrm{L}, \mathrm{K}_{2} \mathrm{HPO}_{4} 1 \mathrm{~g} / \mathrm{L}, \mathrm{KCl} 0.5 \mathrm{~g} / \mathrm{L}$, $\mathrm{MgSO}_{4} \cdot 7 \mathrm{H}_{2} \mathrm{O} 0.5 \mathrm{~g} / \mathrm{L}, \mathrm{FeSO}_{4} 0.01 \mathrm{~g} / \mathrm{L}$, followed by shaking at $200 \mathrm{rpm}$ at $28{ }^{\circ} \mathrm{C}$ for 10 days. At the end of fermentation, all broth was collected and filtered through gauze, which afforded the filtrate (approximate $60 \mathrm{~L}$ ). The filtrate was extracted twice with the same volume of ethyl acetate (Merck). The upper solvent was evaporated at $25{ }^{\circ} \mathrm{C}$ in vacuum to yield the extract (about $2.0 \mathrm{~g}$ ) followed by separation on a semi-preparative HPLC column to afford six fractions (F1-F6) under an isocratic condition of $75 \% \mathrm{CH}_{3} \mathrm{CN}$ in $\mathrm{H}_{2} \mathrm{O}$ with a flow rate of $3.0 \mathrm{~mL} / \mathrm{min}$ and $260 \mathrm{~nm}$ detection. Then bioactive fraction F2 was further subjected to HPLC with an analytical HPLC column $(1.0 \mathrm{~mL} / \mathrm{min})$ to give compounds 1 (2.5 mg, 0.125\%), 2 (5.1 mg, 0.255\%) and 5 (12.2 mg, 0.61\%) under an isocratic condition of $60 \% \mathrm{CH}_{3} \mathrm{CN}$ with a flow rate of $1.0 \mathrm{~mL} / \mathrm{min}$ at $260 \mathrm{~nm}$. Compounds $3(7.2 \mathrm{mg}, 0.36 \%)$ and $4(4.5 \mathrm{mg}$, $0.225 \%$ ) were respectively purified from bioactive fractions F3 and F6 using the same analytical column under an isocratic condition of $65 \% \mathrm{CH}_{3} \mathrm{CN}$.

Tricycloalternarene $14 \mathrm{~b}(\mathbf{1})$ : Yellowish amorphous powder; $\mathrm{C}_{21} \mathrm{H}_{30} \mathrm{O}_{4} ;$ m.p. $59 \sim 60{ }^{\circ} \mathrm{C} ;[\alpha]_{D}^{25}+78^{\circ}$ (c 0.25 , $\mathrm{MeOH}) ; \mathrm{UV}\left(\mathrm{MeOH}, \lambda_{\max }, \mathrm{nm}\right)(\log \varepsilon): 262$ (4.09); IR $\mathrm{V}_{\max } \mathrm{cm}^{-1}(\mathrm{KBr}): 3393,2928,1612,1383,1279$, 1154, 1068, 988, 912; ${ }^{1} \mathrm{H}$ and 13C-NMR data, see Table 1; ESI-MS $m / z: 353[\mathrm{M}+\mathrm{Na}]^{+}$; HR-ESI-MS at $m / z$ 369.2039 $[\mathrm{M}+\mathrm{Na}]^{+}$(calcd for $\mathrm{C}_{21} \mathrm{H}_{30} \mathrm{O}_{4} \mathrm{Na}^{+}$369.2036).

Tricycloalternarene $2 \mathrm{~b}(2)$ : Yellowish amorphous powder; $\mathrm{C}_{21} \mathrm{H}_{30} \mathrm{O}_{4} ;$ m.p. $62 \sim 63{ }^{\circ} \mathrm{C} ;[\alpha]_{D}^{25}+75^{\circ}$ (c 0.49 , $\mathrm{MeOH}) ; \mathrm{UV}\left(\mathrm{MeOH}, \lambda_{\max }, \mathrm{nm}\right)(\log \varepsilon): 263(4.56,200) ; \mathrm{IR} \mathrm{V}_{\max } \mathrm{cm}^{-1}(\mathrm{KBr}): 3420,2920,1720,1650,1618$, $1455,1380,1310,1267,1205,1170,1150,1080,1040,985,915,883,830,820 ;$ EI-MS m/z: 346 [M] $^{+}$. 
Tricycloalternarene 3a (3): Yellowish viscous oil; $\mathrm{C}_{21} \mathrm{H}_{30} \mathrm{O}_{3} ;[\alpha]_{D}^{25}+74^{\circ}$ (c $\left.0.13, \mathrm{MeOH}\right)$; UV (MeOH, $\left.\lambda_{\max }, \mathrm{nm}\right)(\log \varepsilon): 262$ (4.09); IR $\mathrm{V}_{\max } \mathrm{cm}^{-1}(\mathrm{KBr}): 3360,2890,1605,1435,1380,1310,1255,1215,1190$, 1160, 1145, 1080, 1055, 1005, 950, 925, 915, 870, 820, 745; ESI-MS m/z: $353[\mathrm{M}+\mathrm{Na}]^{+}, 331[\mathrm{M}+\mathrm{H}]^{+}$.

Tricycloalternarene $3 \mathrm{~b}$ (4): Yellowish viscous oil; $\mathrm{C}_{21} \mathrm{H}_{30} \mathrm{O}_{3} ;[\alpha]_{D}^{25}+73^{\circ}$ (c $\left.0.20, \mathrm{MeOH}\right) ; \mathrm{UV}(\mathrm{MeOH}$, $\left.\lambda_{\max }, \mathrm{nm}\right)(\log \varepsilon): 264$ (4.14); IR $\mathrm{V}_{\max } \mathrm{cm}^{-1}(\mathrm{KBr}): 3400,2890,1635,1610,1440,1370,1300,1260,1200$, $1165,1145,1075,980,910,875,825,745$; ESI-MS m/z: $353[\mathrm{M}+\mathrm{Na}]^{+}, 331[\mathrm{M}+\mathrm{H}]^{+}$.

ACTG-F (5): Yellowish viscous oil; $\mathrm{C}_{21} \mathrm{H}_{30} \mathrm{O}_{5} ;[\alpha]_{D}^{25}+72^{\circ}$ (c $\left.0.23, \mathrm{MeOH}\right) ; \mathrm{UV}\left(\mathrm{MeOH}, \lambda_{\max }, \mathrm{nm}\right)(\log \varepsilon)$ : 288 (5.50); IR $\mathrm{V}_{\max } \mathrm{Cm}^{-1}$ (KBr): 3400, 2920, 1720, 1680,1642, 1610, 1455, 1370, 1320, 1290, 1260, 1243, $1208,1153,1128,1073,1045,992,945,922,860,805 ;$ ESI-MS $m / z: 385[\mathrm{M}+\mathrm{Na}]^{+}$.

\subsection{Biological Assays}

\subsubsection{Antimicrobial Test}

Three human pathogenic strains, E. coli AB 94012, S. aureus AB 2010021 and C. albicans AY 204006, were purchased from the China Center for Type Culture Collection (CCTCC) and used as antimicrobial indicators in the study. Antimicrobial activity was assessed by the microbroth dilution method in 96-well culture plates developed by Patton and his colleagues [14]. Two positive controls, ampicillin and amphotericin B (Sigma-Aldrich, Buchs, Switzerland), were used as positive controls, and the solution of equal concentration of DMSO was made as a negative control. The bacteria were cultured in the LB medium for $24 \mathrm{~h}$ at $37^{\circ} \mathrm{C}$ at $150 \mathrm{rpm}$, and the tested fungus was incubated in the PD medium for $48 \mathrm{~h}$ at $28^{\circ} \mathrm{C}$ at the same rotatory speed. Bacterial cells or fungal spores were diluted to approximately $1 \times 10^{6} \mathrm{CFU}$ with PD or LB medium to evaluate the antimicrobial activities of pre-HPLC derived fractions and metabolites. Test solution at the initial concentration of $100 \mu \mathrm{M}(100 \mu \mathrm{L})$ was added to 96-well microplate. Two-fold serial dilutions were made in the 96-well round-bottom sterile plates, and then $100 \mu \mathrm{L}$ of the microbial suspension was added. After incubation, minimum inhibitory concentration (MIC) was taken as the lowest concentration of the test compounds in the wells of the 96-well plate in which the lowest microbial growth could be measured at $600 \mathrm{~nm}$. All tests were carried out in triplicate.

\subsubsection{Cytotoxicity Test}

Human lung adenocarcinoma A549 cell line (Shanghai Bioleaf Technology Co. Ltd., Shanghai, China) was grown in RPMI medium with $10 \%$ fetal bovine serum, penicillin $(100 \mathrm{U} / \mathrm{mL})$ and streptomycin $(50 \mu \mathrm{g} / \mathrm{mL})$ and cultured in a 96-well plate at a density of $5 \times 10^{5}$ cells per well. All test compounds and positive control gefitinib (Sigma-Aldrich) were initially made up to $100 \mu \mathrm{M}$ in DMSO. Each isolated compound was added to each well, respectively, with two-fold serial dilutions. Cell line without treatment by compound was used as the control. The incubation was performed in a humidified, $37^{\circ} \mathrm{C}, 5 \% \mathrm{CO}_{2}$-containing incubator for $24 \mathrm{~h}$. Then $10 \mu \mathrm{L} \mathrm{CCK}-8$ dye (Beyotime Institute of Biotechnology, Shanghai, China) was added to each well. Then the cell line was incubated at $37^{\circ} \mathrm{C}$ for $2 \mathrm{~h}$ and plates were read in a Victor-V multilabel counter (Perkin-Elmer, Rodgau-Jügesheim, Germany) using the default europium detection protocol. $\mathrm{IC}_{50}$ value of each compound was calculated by comparison with DMSO-treated control wells and determined by the logit method from at least three independent tests [15].

\section{Conclusions}

This work reported firstly on the chemical investigation of one symbiotic strain Aspergillus sp. D from the coastal plant $E$. chrysantha Lindl. One new meroterpenoid tricycloalternarene $14 \mathrm{~b}(\mathbf{1})$ and four known analogs, tricycloalternarenes $2 b(2), 3 a(3), 3 b(4)$, and ACTG-toxin F (5) were isolated from the crude extract of fermentation broth and unambiguously determined on the basis of their spectroscopic spectra and optical rotation data, as well as by comparison with literature data. Bioassay results 
suggested that these metabolites had moderate cytotoxic effects on A549 cell line in vitro, with $\mathrm{IC}_{50}$ values range from 1.43 to $15.77 \mu \mathrm{M}$, and weak antimicrobial activities against E. coli, S. aureus and C. albicans, with MIC values of $\geq 15.63 \mu \mathrm{M}$. These findings indicated that the symbiotic strain D is one of versatile producers of bioactive tricycloalternarene derivatives with potential application in the field of medicine.

Supplementary Materials: 1D and 2D NMR spectra, and HR-ESI-MS spectrum for compound 1, ${ }^{1} \mathrm{H}$ and $13 \mathrm{C}-\mathrm{NMR}$ spectra for 2, 1H-NMR spectra for 3-5, and LR-ESI-MS spectra for 2-5 are available online.

Acknowledgments: Financial support for this project from the National Key Research and Development Program of China (No. 2017YFE0103100), the National Natural Science Foundation of China (Nos. 41776139, 81773628 and 81741165) and the Zhejiang Natural Science Foundation of China (Nos. LY16H300007 and LQ14C200005) are gratefully appreciated.

Author Contributions: H.Z. conceived and wrote the paper; Z.Z., J.C. and X.B. performed all the experiments; and H.W. made valuable revision.

Conflicts of Interest: The authors declare no conflict of interest.

\section{References}

1. Vadlapudi, V.; Borah, N.; Yellusani, K.R.; Gade, S.; Reddy, P.; Rajamanikyam, M.; Vempati, L.N.S.; Gubbala, S.P.; Chopra, P.; Upadhyayula, S.M.; et al. Aspergillus Secondary Metabolite Database, a resource to understand the secondary metabolome of Aspergillus genus. Sci. Rep. 2017, 7, 7325. [CrossRef] [PubMed]

2. Zhang, H.W.; Tang, Y.F.; Ruan, C.F.; Bai, X.L. Bioactive secondary metabolites from the endophytic Aspergillus genus. Rec. Nat. Prod. 2016, 10,1-16.

3. Bai, Z.Q.; Lin, X.P.; Wang, J.F.; Liu, Y.H. New meroterpenoids from the endophytic fungus Aspergillus flavipes AIL8 derived from the mangrove plant Acanthus ilicifolius. Mar. Drugs 2015, 13, 237-248. [CrossRef] [PubMed]

4. Nussbaum, R.P.; Gunther, W.; Heinze, S.; Liebermann, B. New tricycloalternarenes produced by the phytopathogenic fungus Alternaria alternata. Phytochemistry 1999, 52, 593-599. [CrossRef]

5. Yuan, L.; Zhao, P.J.; Ma, J.; Li, G.H.; Shen, Y.M. Tricycloalternarenes A-E: Five new mixed terpenoids from the endophytic fungal strain Alternaria alternata Ly83. Helv. Chim. Acta 2008, 91, 1588-1594. [CrossRef]

6. Shi, X.; Wei, W.; Zhang, W.J.; Hua, C.P.; Chen, C.J.; Ge, H.M.; Tan, R.X.; Jiao, R.H. New tricycloalternarenes from fungus Alternaria sp. J. Asian Nat. Prod. Res. 2015, 17, 143-148. [CrossRef] [PubMed]

7. Mei, W.L.; Bo, Z.; Zhao, Y.X.; Zhong, H.M.; Chen, X.L.W.; Zeng, Y.B.; Dong, W.H.; Huang, J.L.; Proksch, P.; Dai, H.F. Meroterpenes from endophytic fungus A1 of mangrove plant Scyphiphora hydrophyllacea. Mar. Drugs 2012, 10, 1993-2001. [CrossRef] [PubMed]

8. Wang, Q.X.; Bao, L.; Yang, X.L.; Guo, H.; Ren, B.; Guo, L.D.; Song, F.H.; Wang, W.Z.; Liu, H.W.; Zhang, L.X. Tricycloalternarenes F-H: Three new mixed terpenoids produced by an endolichenic fungus Ulocladium sp. using OSMAC method. Fitoterapia 2013, 85, 8-13. [CrossRef] [PubMed]

9. Kono, Y.; Gardner, J.M.; Suzuki, Y.; Takeuchi, S. Studies on host-selective toxins produced by a pathotype of Alternaria citri causing brown spot disease of mandarins. Agric. Biol. Chem. 1986, 50, 1597-1606. [CrossRef]

10. Sun, H.; Gao, S.H.; Li, X.M.; Li, C.S.; Wang, B.G. Chemical constituents of marine mangrove-derived endophytic fungus Alternaria tenuissima EN-192. Chin. J. Oceanol. Limnol. 2013, 31, 464-470. [CrossRef]

11. Sviridov, S.I.; Ermolinskii, B.S.; Belyakova, G.A.; Dzhavakhiya, V.G. Secondary metabolites of Ulocladium chartarum. Ulocladols A and B-New phytotoxins of terpenoid nature. Chem. Nat. Compd. 1991, 27, 566-571. [CrossRef]

12. Liebermann, B.; Ellinger, R.; Günther, W.; Ihn, W.; Gallander, H. Tricycloalternarenes produced by Alternaria alternata related to ACTG-toxins. Phytochemistry 1997, 46, 297-303. [CrossRef]

13. Yoiprommarat, S.; Srichomthong, K.; Deelai, S.; Suetrong, S.; Sakayaroj, J.; Bunyapaiboonsri, T.; Unagul, P. Secondary metabolites of the marine fungus Paradendryphiella arenariae BCC 17999. Bot. Mar. 2015, 27, 566-571. [CrossRef]

14. Patton, T.; Barrett, J.; Brennan, J.; Moran, N. Use of a spectrophotometric bioassay for determination of microbial sensitivity to manuka honey. J. Microbiol. Methods 2006, 64, 84-95. [CrossRef] [PubMed] 
15. Duan, Y.T.; Yao, Y.F.; Tang, D.J.; Thumar, N.; Teraiya, S.B.; Makawana, J.A.; Sang, T.L.; Wang, Z.C.; Tao, X.X.; Jiang, A.Q.; et al. Synthesis and biological evaluation of quinolineimidazole hybrids as potent telomerase inhibitors: A promising class of antitumor agents. RSC Adv. 2014, 4, 20382-20392. [CrossRef]

Sample Availability: Samples of the compounds 1-5 are available from the authors.

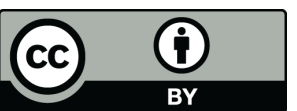

(C) 2018 by the authors. Licensee MDPI, Basel, Switzerland. This article is an open access article distributed under the terms and conditions of the Creative Commons Attribution (CC BY) license (http:/ / creativecommons.org/licenses/by/4.0/). 